\title{
TESOL for Biolinguistic Sustainability: The Ecology of English as a Lingua Mundi
}

\section{Seonaigh MacPherson}

This article examines the ecology between biological and linguistic diversity and the implications for a biolinguistically sustainable approach to TESOL. Drawing on interdisciplinary sources from bio-ecology and anthropology, the article examines the effect of the global spread of English as a lingua mundi in language shifts and extinctions. Consideration is given for how linguistic and biological exchanges are interrelated. Two hypothetical cases are introduced, drawn from the authors ethnographic experience in the Indian Himalayas that demonstrate how the introduction of two English-language discourses can lead to biological, linguistic, and cultural loss. One case involved the introduction of a commercialscientific forestry discourse in an Indian village, and the other the introduction of a psychiatry discourse in a Tibetan refugee Buddhist educational institution. This is followed by a brief description of the actual cases as examples of sustainable biolinguistic (ESL) education. The conclusion considers how to promote more responsible TESOL research and education.

Cet article porte sur le rapport écologie entre la diversité biologique et linguistique dans le contexte d'une approche à TESOL qui est renouvelable sur le plan biolinguistique. Puisant dans des sources pluridisciplinaires en bioécologie et anthropologie, l'auteur se penche sur l'impact qu'a l'étendue planétaire de l'anglais comme lingua mundi sur les transferts linguistiques et l'extinction. Les rapports entre les échanges linguistiques et biologiques sont considérés. Deux cas hypothétiques, relevant de l'expérience ethnographique de l'auteur dans l'Himalaya en Inde, sont présentés pour démontrer la façon dont l'introduction de deux discours en anglais peut entrainer des pertes biologiques, linguistiques et culturelles. Dans un cas, il s'agissait de l'introduction d'un discours commercial sur la foresterie dans un village indien; dans l'autre, de l'introduction d'un discours sur la psychiatrie dans une institution pédagogique bouddhiste pour réfugiés tibétains. Suit une description concise de cas actuels dans lesquels l'éducation en ALS est présentée comme modèle renouvelable sur le plan biolinguistique. La conclusion traite de façons de promouvoir de la recherche et de l'enseignement TESOL plus responsables.

\section{Preface: On the Legacy of a Name-Seonaigh}

The seed of this article was born with my name: Seonaigh (shaw'-nuk). My father chose this Gaelic version of Joanne as a tribute to his sister and their 
shared Scottish Hebridean ancestry, a language and place he knew only through his parents. Similarly, my siblings were called in succession Colin, Lachlan, and Morag. In the end my parents decided Seonaigh was too difficult and so called me Shawny and later Shawn. Forever obstinate, I changed back to Seonaigh at age 22, only to discover the world less amenable to the name than I, and so it was anglicized as Sonia. Initially I tried to correct the error, but was only met with: Why what a strange name!? So I went along with the crowd, calling myself Sonia while Seonaigh remained little more than a lingering curiosity on passports and university degrees, an emblem of a private life beyond the public domain, a singular linguistic shoot with roots deep and entangled in biology and history. Now, as I prepare to move to the prairie region where my Scottish ancestors first settled in Canada, I will try to reclaim my Gaelic name yet again as a sign to remind myself and others of all that has and can be lost with this anglicizing time we inhabit. It has become my enigma, posing the ethical quandry: How to stay the erosion of biolinguistic diversity in our time.

\section{Introduction: On Biolinguistic Diversity}

We and our children are living at the point in human history where, within perhaps two generations, most languages in the world will die out. (UK Foundation for Endangered Languages, 1995)

In the mid-1990s, the World Conservation Union (IUCN) identified as endangered $11 \%$ of bird species and $25 \%$ of mammals of the planet. In an update in 2000 , these rates had increased, with $18 \%$ of the 11,000 threatened species falling within in the most extreme category of "critically endangered" (Worldwatch Institute, 2002, p. 8). Although there is some public awareness of these alarming biological extinctions happening in our time, less is known of the corresponding and interrelated loss of linguistic diversity. As the English language emerges as the lingua mundi of the new global order, human beings are poised to lose $50 \%-90 \%$ of our existing languages within a few generations (Crystal, 2000). Extrapolating from current rates of extinction, Vines (in Lo Bianco, 2000) goes so far as to suggest that only 600 of the existing 6,000 estimated languages will remain by the year 2020, and of those only a small number will be used by large numbers of people. Given the entangled relationship between language and culture, a parallel loss of cultural diversity can be inferred to accompany this linguistic and biological collapse.

When "news" of accelerating extinctions comes to us through public or professional media, are we capable of hearing such "information" properly, or do the figures become yet another bit of information in yet another day, not unlike a weather report? Do we feel unable to respond individually to problems of such planetary proportions; do they just seem like someone 
else's responsibility? Or is it that we somehow doubt the reports, convincing ourselves that it can't be that bad, and if it is, does it really matter? To be sure, one central challenge is to extrapolate realistic predictions from existing demographic information. With respect to language use, for example, numbers of speakers are a crude indicator of a language's viability (Norris, 1998). Languages with over 6,000 speakers are probably safe, but as Crystal (2000) suggests, this depends "on such factors as the rate of acquisition by the children, the attitude of the whole community to it, and the level of impact of other languages which may be threatening it" (p. 19). English poses the greatest threat to global biolinguistic diversity because of its status as the lingua mundi of global communication. As such, it is perceived as a conduit out of local Indigenous communities as the means to access tangible or imagined opportunities and lifestyles. Local languages, in contrast, offer a different attraction and opportunity

to express the identity of the speakers as members of their community. It is inward-looking - but in the best sense-fostering family ties, maintaining social relationships, preserving historical links, giving people a sense of their "pedigree." ... Only the dominated language can refresh the identity of an Indigenous community-the part that other languages cannot reach. (p. 81)

Nettle and Romaine (2000) explore the multiple ways the erosion of linguistic diversity correlates with the loss of biological diversity. So striking is this correspondence between linguistic and biological diversity that these researchers coined a common term: biolinguistic diversity. As with the use of language extinction and death, such terms are needed to shift our perception to appreciate the deep interconnection between language, culture, and biology. One indicator of this interconnection is that areas of high biological diversity correspond with areas of high linguistic diversity, concentrating in equatorial regions where most biolinguistic extinctions will occur and affecting small Indigenous communities most directly. Indigenous people constitute 150 million of the 500 million people living in and around tropical forests and depend directly on forests and forest resources to sustain their lives. One key implication of such biolinguistic entanglement is that linguistic and cultural conservation become important for ecological conservation and vice versa. These relationships challenge our modern conditioned perception that exaggerates distinctions between human and natural worlds.

\section{Why Does Diversity Matter?}

Does diversity even matter-biological or linguistic? After all, some might perceive extinctions as progress, as Darwinian natural selection and evolution making its ineluctable way through history. Even from a narrow anthropocentric, utilitarian position, the fact that we do not know the im- 
plications should give us pause; the risks to human life, not to mention non-human, are simply too great to adopt anything less than the most conservative policies. After all, there are no precedents in recorded history for extinction rates of this magnitude-biological or linguistic. The last of five comparably "catastrophic" biological extinctions happened 65 million years ago at the end of the Mesozoic era when a massive meteorite is believed to caused the extinction of the dinosaurs and other large-bodied species (Wilson, 1992). Human beings did not even exist at that time. Yet here we are in a sixth period of comparable mass extinctions, which we have ourselves induced through climate change, habitat erosion, and resource depletion from overpopulation and overconsumption (Rees, 1999). In tropical rainforest areas alone human activity has increased extinctions between 1,000 and 10,000 times over the average of one species/million annually. As Wilson (1992) concludes, "Clearly we are in the midst of one of the great extinction spasms of geological history" (p. 280)

As regards historical precedents for language extinctions, the closest comparable period of language loss happened 10,000 years ago during the agricultural revolution, which led to the consolidation of languages in temperate agricultural regions. This opened the way for the success of many of the dominant languages today: Chinese (Mandarin and $\mathrm{Wu}$ ), European languages (English, Spanish, Portuguese, Russian, German, and French, in that order), and the South Asian languages of Bengali and Hindi (Nettle \& Romaine, 2000). Later, European colonial assimilation policies established the conditions for the accelerating wave of language extinctions we are experiencing today from globalization. Today the regions of high biolinguistic diversity are those areas historically inhospitable to agricultural or colonial incursions, and most notably the tropical rainforests. Technological advancements and increasing population pressures are forcing overdevelopment into these biolinguistically diverse regions, leading to the erosion and loss of the ecosystem and the diverse species and languages that depend on it.

The biological value of diversity is that the diversity of life sustaining an ecosystem matters more than the survival of any single species. From such a perspective, the continued "health" of the planet Earth as a self-regulating system sustaining and promoting carbon-based life forms is more dependent on the welfare of bacteria than Homo sapiens or any other animal or plant species (Margulis, 1997). This ecosystems view tells us that various life forms on Earth are co-evolving; biologically it matters that the complex relations between species are nested in ecosystems culminating in the planet itself. Yet it is impossible to separate individuals from species from ecosystems from the planetary system sufficiently to identify any "whole" as an end in itself from this biological perspective. So although a single species can prove to be a critical species supporting an entire ecosystem, and its disappearance catas- 
tophic to the underlying ecosystem, identifying such a species is generally difficult and only apparent after the fact. A case in point is the sea otter of the Pacific Northwest, whose disappearance led to the collapse of the entire kelp sea forests ecosystem. As Margulis and Sagan (1997) describe it,

The new knowledge of biology ... alters our view of evolution as a chronic, bloody competition among individuals and species. Life did not take over the globe by combat, but by networking. Life forms multiplied and grew more complex by co-opting others, not just by killing them. (p. 78)

So rather than one species, what is of biological value to sustaining Earth as a context for the sustenance and evolution of life is the network of biological relations-the diversity of life. Even from a more anthropocentric perspective, Beattie and Ehrlich (2001) illustrate how interconnected human beings are to life forms we might consider irrelevant; from bacteria conducting atmospheric regulation to mussels removing pollutants from our waters, our survival and well-being are contingent on the coexistence of diverse life forms. To emphasize the value of biodiversity to human beings, these biologists liken biodiversity to the capital on which human beings withdraw their livelihoods as loans:

The biodiversity of Earth is our biological wealth, our biological capital. The savings are every gene, every population, every species and every natural community that inhabits the oceans, the land, and the air.

Whether we believe that God put them there or that they evolved from earlier creatures, the stark truth remains that they are the only ones we have-there are no life forms anywhere else. (p. 222)

Just as a biosphere is imputed to be the sum of all genetic information on the planet, Davis (2001) posits an interrelated ethnosphere as the sum of information from existing human languages and cultures. In this entangled biosphere and ethnosphere, diversity is an implicit value because we cannot know what information will or will not be relevant to the survival of our species or this planet in the future. In this sense, even from an evolutionary scientific perspective, diversity is an implicit value by virtue of the enhanced biological and cognitive information it avails to future generations. An ethical position would be to go one step further and recognize the intrinsic value of other species as part of the network of life struggling to sustain itself on this planet, and to recognize the intrinsic value of languages in turn because they are entangled in the quality of lives of people adapting to places through time. In this respect, the cost of their loss is not only collective-for the planet or species - but also deeply personal and psychological, as the loss of diversity exacts high costs on the well-being of those most directly affected. As Davis suggests: "What could possibly be more lonely than to be 
enveloped in silence, to be the last person alive capable of speaking your native tongue, to have no means of communicating and no chance of telling the world of the wonders you once knew?" (p. 13).

\section{The Ecology of Language: The Biology-Language Connection}

The shadows cast by Cartesian mind-body dualism make it difficult for the modern consciousness to recognize connections between the linguistic-cultural (as mind) and the biological (as body). This is reinforced by the division of disciplinary knowledge into what C.P. Snow (1959) called "the two cultures" of the sciences and the humanities, and the considerable institutional and scholarly challenge of connecting knowledge across this disciplinary chasm. So although bioecological studies are conducted as if their linguistic and cultural contexts were neutral, linguistic and cultural studies overlook the biological embeddedness of their subjects. Ecology challenges this disciplinary chasm, in part because it refers simultaneously to the scientific study of relationships between organisms and their environments and to the relationships themselves. One pernicious Cartesian shadow is to conceive of "environments" as inanimate, which can mislead people to interpret ecology as the relations between living organisms and inanimate things. It would be more accurate to understand living beings as integral to the ecological niches of other living beings: organisms do not share an environmental niche as much as they serve as a niche to one another. Organisms comprising this living niche include food species, symbiotic species, members of one's own species, and all co-evolving organisms or species in the ecosystem and the multiple systems in which it is nested.

The study of relationships and exchanges is at the heart of ecology. In bio-ecology, the relationships of interest have tended to be energy exchanges of nutriment (biomass), that is, the food chain. In geo-ecology, the emphasis has been on the exchange of fossilized forms of carbon-based energy with the thermal energy of the atmosphere. For the past 20 years, however, ecologists of different backgrounds have begun to recognize that consciousness or mind is integral to the ecology of this planet. From Bateson's (1972) ecology of mind to Maturana and Varela's (1987) biology of cognition, scholars and scientists have struggled to understand and represent the relationship between mechanistic biological exchanges and cognitive exchanges in an ecosystem. As we struggle to eat and survive in an ecosystem, we learn adaptively significant "knowledge" ranging from conditioned responses to conceptual ideas. These "ecologies of mind" are both between and within species. Such exchanges occur in a context of emotional bonding where knowledge is first signified-that is, made significant-by the emotional context and its underlying biochemical dimensions, what Pert (1997) calls "molecules of emotion." The more developed and intelligent the species is, 
the more dependent it is on this emotional-social niche, at least in the formative stages of individual development.

Human beings refined this ability to exchange adaptively significant information manifold with the development of language. Language and culture became indistinguishable from our adaptive niche to the extent that it is impossible to conceive of a human being surviving from birth to maturity without the context of language and culture to sustain them. Language is thought to have emerged from our primate ancestors' grooming habits, as a form of "gossip" reinforcing social cohesion and intraspecies bonding; however, with time it developed into a highly successful source of environmental information exchange (Ehrlich, 2000). Initially language would have bonded members in local communities, ${ }^{1}$ but as its informationexchange potential increased, there would have been added pressure to speak a common language across communities of increasing biological and ecological differences. This would augment the genetic, resource, and environmental-information exchange potential of the language. This points to a key justification for the global spread of English as the principal language of exchange of scientific information. Yet the adaptive value of any language is lost if the local significance (to mating, resources, and the environment) is sacrificed in global information exchanges. This is a compelling justification for the promotion of bilingualism in local and regional or global languages.

Motivation and volition are key factors in the success of bilingualism. Yet it is difficult to recognize the value of conserving a local or native language when the potential loss of quality of life takes place over generations. As Ehrlich (2000) argues, "The difficulty is that the most serious threats now faced by humanity are slow, deleterious changes in the environmental background itself, changes our perceptual systems have evolved to encourage us to ignore. These are changes that take place over decades-population growth, gradual alteration of the climate through global warming, loss of biodiversity, land degradation ... and the like" (p. 136). Similarly, language loss tends to occur over three generations (Nettle \& Romaine, 2000), during which time we can become inured to the deleterious effects of what is lost. Aggravating this is the tendency for the modern sensibility to perceive all change as necessarily "progressive," which is absurd given that we are capable of normalizing or habituating to the worst atrocities. Instead, what is required is more than mere "information," but also the cultivation of a more sensitive and ethical awareness and perception of change. In this we might heed the warnings of Ehrlich (2000):

The evolution of the tendency to habituate apparently allows us to behave in ways that otherwise would be inexplicable ... Obvious examples are the loss of sensitivity to the effects of horrendous violence that affected many of Hitler's executioners and that today influences children who watch multitudes of murders on television. Here, the con- 
stant environment of violence gradually becomes the "normal" environmental background and fails to elicit socially appropriate responses.

(p. 136)

\section{A Not-So-Natural History: Which Human Languages (and Cultures) Dominate and Why}

An examination of the current global distribution of human languages shows that the dominant human languages come from two principal linguistic groups: Chinese and Indo-European. Not coincidentally, these groups also have the largest populations (Chinese; South Asian; and European and descendants), which indicates the close correlation between linguistic and population dominance. From this and other ethnolinguistic evidence (Nettle \& Romaine, 2000), we can determine that linguistic dominance is not based on an implicit superiority in linguistic potential, that is, in grammatical or lexical complexity; nor is it related to social complexity, well-being, or moral superiority. Rather, the linguistic and cultural dominance of Indo-European and Chinese peoples appears to arise from sheer population dominance.

This constellation of language-culture-population advantage stemmed from three significant historical economic (human ecological) revolutions:

1. The agricultural revolution, over 10,000 years ago, led to the development of more sedentary lives through crops and domestic animals; this enhanced the quantity but not the quality of human lives. Disease, starvation, hardships, droughts, and soil erosion all increased, as did infant mortality and the number of women dying in childbirth.

2. The scientific-industrial revolution, beginning in about 1750 , marked another shift in human ecological relations through the exploitation of fossil fuels (Rees, 2002).

3. The technological revolution has contributed to the accelerating loss of biolinguistic diversity in our time. Technologically linked biological and linguistic monocultures are arising from genetically modified seed crops, cloned livestock, and information media.

These three revolutions gave rise to four key innovations and/or social practices that gave Indo-European and Chinese societies significant population advantages (Diamond, 1999).

1. Food production innovations arising from the domestication of large mammalian livestock and the cultivation of crops, which led to a sedentary lifestyle.

2. The technological innovations of gunpowder and printing presses. (The Chinese did not develop the same sophistication in these technologies as Europeans, who gained in competitive advantage accordingly.)

3. Innovations in writing that permitted the transmission and distribution of elaborate forms of cultural knowledge, which in turn gave rise to a leisured, scholarly class. 
4. Political reorganization through imperialist unification movements, which generated large armies and brutal regimes, which in turn carried out the forced assimilation of marginal or opposing peoples.

In this sense it should be apparent that population and linguistic advantage do not necessarily accompany greater well-being, ethics, or civility, even if associated with supposed "civilizations."

\section{Endangered Ecosystems: The Erosion of Biolinguistic Diversity in Our Day}

When comparing maps of global biological and linguistic diversity (Nettle \& Romaine, 2000), two trends emerge: (a) areas of biological diversity correspond with areas of linguistic diversity; and (b) the areas of greatest biolinguistic diversity are in the tropics. Hunter-gatherers, still victims of agricultural aggression, have and continue to congregate in eco-regions not amenable to agricultural development and colonization. In the process, these tropical bioregions became pockets of high biodiversity because: (a) the climate promotes greater biomass generally, and (b) by excluding agriculture and agricultural peoples, the ecosystems avoid the biological monocultures arising from agriculture. They promote high linguistic diversity among their Indigenous hunter-gatherer peoples because: (a) the dense vegetation and other natural barriers isolate small linguistic communities; (b) languages and cultures become specialized to deal with small, specialized ecosystems; and, most significantly, (c) these ecosystems do not just keep community members in, they keep colonizers out, and with them their assimilative languages, cultures, education, and economic organizations.

Today, with globalization and its accompanying technological innovations and human population pressures, even these natural barriers are surmounted. As tropical regions of high biolinguistic diversity become more accessible to dominant populations and technologies, their biolinguistic diversity comes under imminent threat. Nettle and Romaine (2000) estimate that of the 5,000-6,000 estimated languages in existence today, at least 50\% will be extinct by the end of this century. These extinctions will affect small Indigenous communities most directly. In Canada, one of the leading sources of demographic data on the topic, only three of Canada's 50 Aboriginal languages have sufficient populations to be considered secure (Norris, 1998). Nettle and Romaine use terms like death and extinction with reference to languages to emphasize the real loss of biological information associated with the loss of diversity, not to mention cultural diversity: "Linguistic diversity ... is a benchmark for cultural diversity. Language death is symptomatic of cultural death; a way of life disappears with the death of a language" (p. 7).

In this respect the fate of linguistic diversity is an indirect indicator of the fate of cultural diversity. Furthermore, this suggests that the loss of a lan- 
guage entails a real loss of knowledge about our world, human history, and adaptation. To understand this loss of knowledge, it is helpful to begin with processes of language loss and assimilation, which are easier to track than the loss of cultural knowledge per se. The factors range from unintentional to intentional assimilation, and involuntary and voluntary language shift.

1. Language loss through population loss. In some cases languages become extinct in a short period because the population of native speakers dies out through disease and/or genocide.

2. Involuntary (forced) language shift. Assimilation takes place on a spectrum from forced to voluntary. Forced language shift arises through abusive government policies related to education, Indigenous peoples, and the forced migration of minorities. In the case of Canada and Australia, the forced residential schooling of Indigenous children is an example, as is the Mandarin-dominated higher education in Tibet.

3. Voluntary language shift. In most contemporary cases, the loss of the Indigenous or mother tongue appears to be volitional; however, this can be misleading in that power inequities make volition a problematic concept with respect to language loss (Bourdieu, 1991). A better distinction might be whether the shift is based on an informed or uniformed choice. For example, children born to immigrant parents may appear voluntarily to stop speaking their native language once they begin school, yet they are not in a position to understand the long-term implications of this loss to themselves, their families, or the wider society.

4. Public versus private language shift. A final distinction concerns whether the choice to shift from a local to a dominant language is being made in the public or private domain. This leads to distinctions between top-down vs. bottom-up language shift, and home versus institutional language shifts. In top-down language shift, the language is lost in the public domain (government, media, education) but maintained in the home; this is the case in some regions of Tibet where Mandarin has been forcibly imposed in public institions. A bottom-up shift occurs when the language stops being used in private, but is conserved for public, formal, or scholastic purposes; examples are Latin, much of Irish Gaelic, and Sanskrit. The key site for linguistic conservation of a language is private home use, which is why so many bilingual policy experts argue for bottom-up language support policies (Hornberger, 1997).

\section{Biolinguistic Diversity as Adaptive "Information"}

The central premise of this article is that biolinguistic diversity constitutes a form of stored knowledge in the biosphere-ethnosphere, a type of ecological information of unknown evolutionary significance to the evolution of our species and the planet Earth. Although bio-ecology emphasizes the exchange 
of energy, the spectrum of exchanges between organisms and their environments goes well beyond energy. Continual exchanges of "information" condition and recondition our patterns of relating. In our current state of mass extinctions, the loss of biolinguistic diversity constitutes a "catastrophic" (Wilson, 1992) loss of ecological information of potential significance to human and planetary survival and evolution. The loss of a biological species is a real loss of biological-both genotypic and phenotypic- "information"; that is, it is lost to the genetic pool and as a support species to other plants and animals, including humans. Similarly, the loss of languages and cultures entails real losses of ecological information. To appreciate this relationship, language needs to be recognized as more than a neutral mediator of translatable abstract knowledge, just as the "real" world needs to be recognized as more than the aggregate of objective "matter." The world we "know" is an emergent phenomenon of objective and subjective factors, including perception and language. Languages embody culturally memorialized relations between humans and their niches, including relations with their own bodies, minds, and relationships with humans and nonhumans alike.

\section{The Bio-Linguistic "Information" Exchange: Two Hypothetical Cases}

To illustrate how the introduction of English can lead to the loss of biolinguistic diversity, I offer two hypothetical cases that arise from my observation that a key justification for introducing English in traditional communities is to avail the community of discourses entangled in the English language. The discourses tend to be development-related topics of a scientific, economic (industrial, business, management), or professional nature. The English language can precede the discourse through media, tourism, or education, but the discourses eventually follow. In these cases the discourses were the point of contact with the language. These cases are derived from research I conducted in the Indian Himalayas; they are hypothetical in that they infer a sequence of effects in the absence of local resistance to the offending discourses. In point of fact, innovative project leaders anticipated the potential deleterious effects and so either adapted or actively resisted the introduction of the discourses in question. The two cases are: (a) the introduction of a scientific forestry discourse in an Indian village, and (b) the introduction of a medical psychiatric discourse in a Tibetan refugee settlement. In both cases the circular network of relations might be represented as:

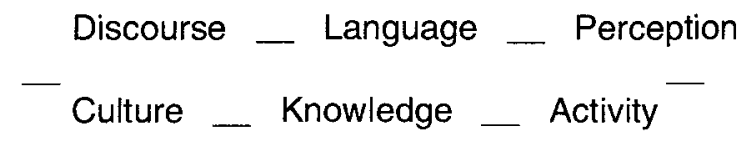




\section{Case \#1: The Introduction of a Scientific Forestry Discourse in a Himalayan Village}

The first example is the introduction of a scientific forestry discourse in an Indian Himalayan village. The context was a collaborative project funded by an international development agency, but jointly administered by an Indian university forestry department, the state government, and local villages. Shiva (1993) used a similar case to illustrate how biological and cultural monocultures co-arise. Fortunately in this case, great attempts were made to develop the project using a village-based agro-forestry model appropriate to sustaining local communities, cultures, and well-being. The hypothetical case I offer here, in contrast, is an attempt to describe what might have happened had the project been developed exclusively in a scientific and commerical forestry model:

\section{_ Discourse _ Language}

Like most scientific discourses, modern forestry is entangled in the English language because it is dominated by Western English-speaking universities, research and development agencies, and publications. In turn, the introduction of development projects based on the discourse exert subtle pressures to shift to English to conduct environmental, educational, commercial, and professional activities. Whether the discourse is communicated through a translator or directly in English, the slippage begins with initial contact at the level of language, as when a tree or a forest becomes reduced and represented by the utilitarian terms wood and lumber. In contrast to tree and forest, the terms wood and lumber misrepresent the forest's complex relationship to the village, belittling or negating its agricultural (fruit, nuts, and fodder), water, and spiritual value.

\section{_ Language _ Perception}

Although the shift begins in language, it soon becomes a shift in perception as people stop attending to the agricultural and spiritual dimensions of their experience of the forest. With the slippage from trees to wood and lumber, for example, the traditional perception of trees and forests as living beings or places of intrinsic value with spiritual significance erodes. Instead, trees and forests become perceived as mere material resources for economic exploitation.

\section{Perception - Activity}

The diminished perception of the forest's capacity to satisfy the villagers' multiple needs (water, fuel, medicine, food, fodder, spiritual and historical) alters how they interact with the forest. They may stop searching for water, food, fodder, and spiritual solace in the forest; perhaps they visit there simply to "harvest" wood or to travel to the next village, where the forest is little more than an obstacle. Progressively more of the forest is perceived as 
superfluous to its commercial "purpose," reduced now to the harvesting of wood and lumber. Streams are diverted to build a road; the forest floor is stripped to access trees; high-yield wood varieties are planted in lieu of indigenous fruit and nut trees. As fewer women venture to the forest to collect food, medicines, water, and fodder, more men go there as lumberjacks; soon the forests are perceived as dangerous places for women, the group most invested in traditional Indian village-based forest practices.

\section{_ Activity _ Knowledge}

As human activities in the forest shift to those identified with the modern forestry discourse, traditional knowledge about how to interact with or in the forest is eroded. Knowledge of where and how to locate sources of water, the plants with special medicinal values, the edible and inedible plants, the tracks of animals, and how to interpret the sounds of the forest are all diminished over time. In the end, if any such knowledge survives, it is perceived as the quaint superstitions or sentimentalized stories of the elderly.

\section{_ Knowledge _ Culture}

As they lose knowledge of the historical and spiritual significance of the forest to their community and cultural identity, the local people shift to view the forest as a simplified and uniform "resource." As the monolithic modern utilitarian view of forests supplants the local culture, generating what Shiva (1993) calls a "monoculture of the mind," the forest ecosystem is similarly transformed into a high "wood" yield forest monoculture. In this way the emergence of biological and mental monocultures coincide. This monoculture of the mind is more than uniform information; it is a uniform consciousness and culture, with a distinctive and selective manner of attending, perceiving, and responding to the world: the global modern.

\section{Case \#2: The Introduction of a Psychiatric Discourse in a Tibetan Buddhist Nunnery}

Ecologies of linguistic-cultural-biological exchanges not only affect how we use environments "out there," they affect how we use our body-minds "in here." In this sense the loss of certain languages and the discourses they embody bears significantly on our evolution. Nonmodern cultural knowledge and nonmaterial "technologies" of development are embedded in languages that condition the human body-mind in unique ways; such "information" is at high risk in the current wave of biolinguistic extinctions. The hypothetical case I use to illustrate this is the introduction of a psychiatric discourse in an educational institute for Tibetan refugee nuns.

I draw this hypothetic example from a research site in the Indian Himalayas, where I taught and conducted research. This educational institute and nunnery was developed in the 1990s for the refugee Buddhist 
nuns streaming from Tibet (MacPherson, 2000, 2001a, 2001b). Over 10\% of the students were former political prisoners tortured in Tibet under the Chinese occupational regime, who showed symptoms of what Western psychiatrists would label posttraumatic stress disorder (PTSD). Others suffered under the lower altitude, higher temperatures, increased bacteria and disease, and general malaise of life in exile by succumbing to multiple health challenges, including tuberculosis, dysentery, typhoid fever, scabies, and homesickness (depression, malaise). So in addition to introducing the nuns to basic ESL literacy, I became an on-site healthcare worker responsible for referring more serious cases to the hospital. We also launched a healthcare ESL training program to help the nuns become more self-sufficient, which involved teaching a select group of nuns in basic healthcare practices, including basic English terminology to negotiate consultations with various medical services and specialists.

I was asked to teach the English-language component and was given background support materials. I noticed the one medical specialization conspicuously missing from the list was psychiatry. The administration politely indicated that I was not to introduce even the terminology to make such referrals possible. By this point, many of the former victims of torture seemed well adjusted, with few if any lingering symptoms of PTSD. To date the nunnery had resisted the World Health Organization and other international bodies who wished to monitor or treat these nuns. Once a month a Dutch WHO physician visited the nunnery, but the administration resisted all but the most cursory examinations. The Director told me they believed their own culture and education would do a better job than singling the tortured nuns out unnecessarily for therapuetic interventions. They believed a good education, supported by a warm and inclusive community, was better than even the most effective therapy.

To understand the administration's reluctance, it is helpful to appreciate the sophisticated mind-science underlying Tibetan Buddhist monastic education. Tibetans sustained and developed this remarkable body of knowledge and meditative technologies to cultivate and refine human consciousness. Through training in concentration and insight, students develop awareness, intelligence, discipline, and altruism. First inherited from India between 800-1200 CE, the texts, teachers, and practices were later lost in India under the violent reign of invading Turkish marauders. The education promoted rigorous philosophical analyses and the phenomenological investigation of experience. The rationale for the education system was to train the mind, based on the view that mind, though dependent on material (physical) factors, cannot be reduced to them; consciousness arises from a different causal continuum than that of matter. This is in marked contrast to the objective, materialist and reductionistic view of mind propagated by much of science, and especially psychiatry. The two views of mind are not necessarily 
in conflict, however, as HH the 14th Dalai Lama suggests, "Eastern philosophy and Western science could be a good marriage, without a divorce." Regrettably, the scientific view is not so generous and remains indifferent to non-Western perspectives and uncritical of its own reductionistic views.

The material reductionism of Western psychiatric mind-science has made it overly reliant on biological explanations and hence on biochemical drugs to treat problems of a mental nature. A good example is the use of Ritalin (an amphetamine) in the treatment of ADHD in young boys, in contrast to the conspicous absence of any effort to educate their attention directly (as through calm-abiding meditation). Tibetans have a deep and abiding confidence in the Buddhist view and treatment of mind, and so resisted introducing even the language that would have made a referral possible (there were psychiatrists at the local Indian hospital). Nevertheless, in this hypothetical case, I consider what might happen if a psychiatric view of mindscience were introduced:

\section{Discourse — Language}

In this hypothetical case, let us assume that I do teach English medical terminology, thus enabling the healthcare worker nuns to refer patients to a psychiatrist. The slippage leading to the loss of biolinguistic knowledge begins with the introduction of English diagnostic vocabulary even before any medical referrals. Replacing the varied and nuanced Tibetan terms for mind with English terms like brain, biochemicals, and blood negates the Tibetan view that mind cannot be reduced to matter. If anywhere, they locate the mind in the heart area of the body, not in the brain. Furthermore, mental distress and disorders are endemic to the untrained mind; any moment of consciousness involves the intersection of physical (sensori-perceptual), conceptual, and emotional components, and short of the full realization of wisdom and compassion (specifically defined), such a consciousness has some degree of affliction. So the main task for liberation from mental afflictions is to examine the consciousness, not the brain, blood, or biochemicals.

\section{_ Language _ Perception}

With the introduction of English psychiatric diagnostic categories, the healthcare worker nuns start to perceive shifting states of mind as caused by body / brain chemistry and propagate the same view in their encounter with other nuns and patients. With the shift in language, the perception gradually develops that mind states are somehow out of people's conscious control. As they perceive their bodies acting in their changing mind states, their sense of personal responsibility may be eroded, and with it their belief that they can affect or correct subtle mental dis-eases like restlessness, anxiety, anger, jealousy, excitation, and depression. 


\section{_ Perception _ Activity}

When their minds become unsettled, as minds eventually do, rather than turning to their Indigenous practices of meditation to correct subtle "sinking" or "excitation," the nuns learn to remain passive in the face of growing mental disfunction. Some infer that physical interventions will help and so do physical exercise and dietary adjustments; in others the disorder may persist and lead them to the psychiatrist, who prescribes drugs and biochemical interventions. These interventions can create biochemical imbalances that require future interventions (Pert, 1997).

\section{Activity _ Knowledge}

By learning to rely on medication rather than meditation, the patients lose their learned ability to correct the mind on an ongoing basis; eventually this may lead them to lose confidence in the ability of meditation to correct mental imbalances. They lose the direct evidence of experience that is vital to maintaining and sustaining a meditative practice. As the experience is lost, so is the knowledge that transmits this complex and sophisticated discourse and system of mind training.

Knowledge - Culture

As the knowledge is lost, fewer women are drawn to the monastic life as a path to liberation, because such freedom is dependent on the practice of meditation. More come to adopt the skeptical view that religion and the life of monastics are somehow superstitious or oppressive. By leaving the lifestyle, this rich, subtle cultural system for training the human body-mind is lost, and with it its underlying effects on psychological, biochemical, and anatomical functioning (Kabat-Zinn, 1990; Austin, 1998; Bruce, 2002). Also lost is the unique path of cultural, and ultimately biological, evolution that such an elaborate and singular system of education generates. Thus the "monoculture of the mind" represented by psychiatry gives rise to a biological monoculture in how human beings develop and use their own bodyminds.

\section{The Actual Cases: Models of Biolinguistically Sustainable Educational Development}

In both cases described above, the intervention of careful project leaders mitigated the effect of the English-language discourses, which did not as a consequence prove as deleterious as the hypothetical worst-case scenarios. In the case of the Indian village, the university negotiated with the local village council to arrange a local council of women to oversee the project, some of the women most affected by the health of the local forest. This organizational buffer allowed sufficient cultural and linguistic distance between the funding agencies, the university, and the village to stay some of the negative effects that might have arisen from more direct contact. The state govern- 
ment provided indigenous fruit and nut tree seedlings to encourage the women to feel an investment in the long-term sustainability of the forest, and the university liaison offered agroforestry skills development sessions locally in their Indigenous language. Many villages in the region have not been so fortunate (Cranney, 2001).

In the case of the educational institution for Tibetan refugee nuns, the healthcare workers' training was developed to target their language learning to access only those aspects of Western medicine appropriate to their needs. So although they learned to distinguish symptoms of a viral from a bacterial infection, they also learned to refer nuns with evidence of bacterial infections to the Western medical facility, but use the traditional and more preventionoriented Tibetan medical system for other conditions (e.g., indigestionwhat the nuns called poa). This has the added benefit of freeing their time for their Buddhist philosophical studies. I taught this healthcare English-language program in 1992, and later in 1998, and developed a system for introducing the terminology in an adapted version of their dialectical debate (called tsen-nyi or "definitions and divisions"). In this way I tried to make the method by which the language was introduced culturally familiar and appropriate.

Although selected to show the entanglement of linguistic (cultural) and biological diversity, these cases offer insights into how to develop biolinguistically sustainable education and ESL programs. In the agroforestry program, for example, the project developers resisted introducing either the English language or its accompanying modern discourse unnecessarily. When I visited the project, the university professor/liaison translated so that I could converse with the village women. It may seem contradictory to suggest that ESL teachers and administrators advocate not teaching or introducing English in some circumstances, but to do so is, in my view, a matter of professional ethics. Development-whether economic or educational-is not after all an inherent good; therefore, informed choices need to be made at the point of initial contact. In the case of the nuns, the administrators carefully targeted the introduction of English to offer students appropriate and sufficient knowledge of the new language and discourse to promote their well-being. Both these strategies point to the importance of identifying key target sites of contact between the Indigenous and introduced languages and discourses, and then making decisions bearing in mind the best long-term interests of both the community's and students' well-being.

\section{The Way Ahead: Biolinguistically Sustainable ESL Education}

In applying the concept of biolinguistic sustainability, the community's interest in education can be better protected. The language of sustainability offers a way to integrate considerations of linguistic and cultural diversity and well-being into national and international development decision- 
making, given that ecological sustainability is currently a ubiquitous criterion for assessing development projects. What it means to exchange languages and cultures in a sustainable manner is comparable to the sustainable exchange of energy; it is to act in such a way as to conserve biolinguistic diversity at current or higher rates. As a discourse, sustainability is linked to a constellation of related concepts useful to conserving languages and cultures. The concept of the ecological footprint, for example, developed by Wackernagel and Rees (1996) offers a way to quantify the amount of energy we consume in relationship to our sustainable share. This could be applied to posit an eco-linguistic footprint as an indicator of the effect of personal lifestyle, decision-making, and professional activity on global linguistic sustainability -or perhaps even an eco-biolinguistic footprint that combines both biological and linguistic sustainability.

In February 1992, UNESCO convened a group of linguistic "experts" to address this imminent crisis in biolinguistic loss, which concluded with a call for "world solidarity" to preserve "the non-physical cultural heritage" of endangered languages. One of the principal recommendations was to constitute a number of regional ecological language reserves to protect the endangered or dying languages (Crystal, 2000). Lo Bianco (2000) suggests that the emphasis on research and "human 'museumification" is "impotent and questionable," deflecting attention from the "crime of linguistic genocide" arising from what Skutnabb-Kangas and Phillipson (1995) call linguicism. These varied researchers identify the spread of English through language planning and "linguistic market forces" as most culpable for this unconscionable state of affairs. By interpreting the crisis as "a crime" of ethical and legal import places the onus of action on international and national constitutional and human rights law. After all, as important as such legal initiatives may prove to be in the long term, they offer little hope of addressing the crisis in the short term.

The challenge is that although local languages enhance psychological well-being, fluency in standard English can offer important economic and educational opportunities. So the task is not so much to determine which language is of greater importance as how to promote each language in its appropriate educational and social context. For this reason most linguistic specialists point to sustainable (Crystal, 2000), additive (Cummins, 2001), and bottom-up (Hornberger, 1997, 1988) bilingualism as the solution (Krauss, 1998; Nettle \& Romaine, 2000). Such bilingualism eliminates the necessity of a choice between local identity and global opportunities. Yet what gives us pause is that bilingualism-the subtractive or "unconstructive" variant-is also a stage in cultural assimilation that leads to biolinguistic demise. As Crystal (2002) explains, language extinction progresses through three stages: (a) pressure to use a dominant language; (b) emergent bilingualism; and (c) language shift leading to moribundity and eventual 
extinction. It is difficult to influence the pressure to use English, which is ubiquitously perceived as a precondition for economic and educational advancement; and by the third stage, the prospect of reviving a local language is remote. So the key stage for intervention seems to be the second, that is, the stage of emergent bilingualism.

Understanding how English can be introduced and taught to support the robust survival of local and Indigenous languages needs to become the centre of TESOL activities rather than a footnote in our education and texts. Activities to support this shift include theoretical innovations such as the development of a theory of eco-linguistics and ecology of language with complementary SLA theories to accompany them. Possible methodological implications include: (a) using content-based instruction while containing English to targeted discourses to avoid the attrition of native discourses; (b) adapting programs to incorporate local genres, genre-preferences and casestudies (Reyhner, 1997; MacPherson, 2001a, 2001b); (c) enhancing connections and opportunities between the first and second languages and literacy (Drapeau, 1992); (d) attending to identity resistances and intercultural identity and skills development (Kim, 2001); and (e) attending to the local and particular rather than a universal method (Kumaravadivelu, 2001). In this sense, more than a method per se, what is called for is a turn-a serious turn-to the question of ethics.

Courses and conversations on ethics at all levels of the profession are required to grapple with this issue, which is at heart a question of values. Given that so many linguists, anthropologists, and cultural commentators concur that the spread of English is a key aggravating factor in the demise of languages and ecosystems (Nettle \& Romaine, 2000; Crystal, 2000), it is our responsbility to understand the implications of our professional activities. At present there is a tendency to relegate these troubling implications of our activities to the neglected margins of our discipline, where the political (Skutnabb-Kangas \& Phillipson, 1995), cultural (Pennycook, 1994), social (Norton, 2000), and ecological contexts of TESOL remain parenthetic to the central project of propagating the language. Understanding the effect of the spread of English on these varied contexts has become tangential to the project of perfecting the "technologization" of second-language acquisition-what Block (2002) calls "McCommunication." Research and conversations about "what works" need to be complemented by a critical awareness of the broader ethical implications if and when a method does work. As Canagarajah (2002) suggests, the preoccupation with method serves the marketization of TESOL and undermines the diversity of languages and communities:

The methods trade parallels in many ways the traditional commercial relations in industrial products in the international market.... Centre methods may make an assault on alternative styles of thinking, learning, and 
interacting preferred by other communities. They may limit critical thinking and impose homogeneous values and practices. (p. 135)

Perhaps our greatest challenge is to shift our perception itself to understand that when we change languages we change the world. Perhaps the American Aboriginal principle of acting on behalf of seven generations is a useful way to cultivate such a perception. It is becoming apparent that our generation is in a critical period when the future of our species and planet is being determined. To accept a TESL job at a university in New Guinea, for example, is to accept responsibility for the potential erosion of more languages and species than in most of the rest of the world combined; it is no longer adequate to plead ignorance. This is not only about what happens in remote regions either; globalization has implicated us directly in the fate of all ecosystems and regions of the world. To struggle to integrate an Aboriginal student in Canada without addressing her or his first language and culture, to not understand her or his resistance to schooling as a potential act of survival, is to be implicated in this imminent "catastrophe." We may not have much time to change either, as the biologist Myers (2001) suggests:

I would say that the length of time we have to get our act together and try to slow and stem this mass extinction is no more than ten years, and I say that because after that the processes of habitat destruction, especially the grand scale deforestation in the tropics where most species exist, those processes of destruction will have worked up so much momentum, we shall hardly be able to slow them down, let alone stop them. (n.p.)

\section{Note}

${ }^{1}$ Ehrlich (2000) summarized research by psychologist Robin Dunbar and anthropologist Leslie Aiello that "anatomically modern human beings.... have a basic group size of $90-220$ individuals, which bracket the number, 148 , that was statistically predicted from the relationship between the neocortext-brain volume ratio and group size" ${ }^{\prime \prime}$ (p. 157).

\section{The Author}

Seonaigh MacPherson received her doctorate from the University of British Columbia in 2000 for ethnographic research on language and education at a Tibetan Buddhist nunnery in the Himalayas. For the last two years she has been at the University of Alberta researching and writing on the education of ecological world citizens, a project funded by a Killam postdoctoral research fellowship. In the spring of 2003 she begins as an assistant professor in TESL Education at the University of Manitoba.

\section{References}

Austin, J.H. (1998). Zen and the brain: Toward and understanding of meditation and consciousness. London: MIT Press.

Bateson, G. (1972). Steps to an ecology of mind. Chicago, IL: University of Chicago Press.

Beattie, A., \& Ehrlich, P. (2001). Wild solutions: How biodiversity is money in the bank. New Haven, CT: Yale University Press. 
Bourdieu, P. (1991). Language and symbolic power. Cambridge, MA: Harvard University Press. Block, D. (2002). "McCommunication": A problem in the frame for SLA. In D. Block \& D.

Cameron (Eds.), Globalization and language teaching (pp. 117-133). London and New York: Routledge.

Bruce, A. (2002). Abiding in liminal spaces(s): Inscribing mindful living/dying with(in) end-of-life care. Unpublished doctoral dissertation, University of British Columbia.

Canagarajah, A.S. (2002). Globalization, methods, and practice in periphery classrooms. In D. Block \& D. Cameron (Eds.), Globalization and language teaching (pp. 134-150). London and New York: Routledge.

Cranney, B. (2001). Local environement and lived experience: The mountain women of Himachal Pradesh. Thousand Oaks, CA: Sage.

Crystal, D. (2000). Language death. Cambridge, UK: Cambridge University Press.

Cummins, J. (2001). An introductory reader of the uritings of Jim Cummins. Toronto, $\mathrm{ON}$ : Multilingual Matters.

Davis, W. (2001). Light at the edge of the world: A journey through the realm of vanishing cultures. Vancouver, BC: Mouglas \& McIntyre.

Diamond, J. (1999). Guns, germs, and steel: The fates of human societies. New York and London: Norton.

Drapeau, L. (1992, August). Language birth: An alternative to language death. Paper presented at the XVth International Congress of Linguists, Quebec.

Ehrlich, P. (2000). Human natures: Genes, cultures, and the human prospect. Washington, DC: Island Press.

Hornberger, N. (Ed.). (1997). Language planning from the bottom up: Indigenous literacies in the Americas. Berlin: Mouton de Gruyter.

Hornberger, N. (1988). Bilingual education and language maintenance: A southern Peruvian Quechua case. Providence, RI: Foris.

Kabat-Zinn, J. (1990). Full catastrophe living: Using the wisdom of your body and mind to face stress, pain and illness. New York: Delacorte.

Kim, Y.Y. (2001). Becoming interculture: An integrative theory of communication and cross-cultural adaptation. Thousand Oaks, CA: Sage.

Krauss, M. (1998). The condition of Native North American languages: The need for realistic assessment and action. International Journal of the Sociology of Language, 132, 9-21.

Kumaravadivelu, B. (2001). Toward a postmethod pedagogy. TESOL Quarterly, 35, 537-560.

Lo Bianco, J. (2000). Multiliteracies and multilingualism. In B. Cope \& M. Kalantzis (Eds.), Multiliteracies: Literacy learning and the design of social futures (pp. 92-106). New York and London: Routledge,

MacPherson, S. (2000). A path of learning: Indo-Tibetan Buddhism as education. Unpublished doctoral dissertation, University of British Columbia.

MacPherson, S. (2001a). An alternative enlightenment praxis: Tibetan Buddhist monastic education. International Journal of Curriculum and Instruction, 3(1), 97-114.

MacPherson, S. (2001b). A genre to remember: Tibetan popular poetry and song as remembrance. Language and Literacy: A Canadian Educational e-Journal. Available: http:// educ.queensu.ca

Margulis, L., \& Sagan, D. (1997). Slanted truths: Essays on Gaia, symbiosis and evolution. New York: Springer-Verlag.

Maturana, H., \& Varela, F. (1987). The tree of knowledge: The biological roots of human understanding. Boston, MA: Shambhala.

Myers, N. (2001, June 16). The coming extinction. Quirks and Quarks, CBC-Radio.

Nettle, D., \& Romaine, S. (2000). Vanishing voices: The extinction of the world's languages. New York: Oxford University Press.

Norton, B. (2000). Identity and language learning: Gender, ethniciy and educational change. London and New York: Longman. 
Norris, M.J. (1998). Canada's Aboriginal languages. Canadian Social Trends. Winter, Statistics Canada-Catalogue No. 11-008, 8-16.

Pennycook, A. (1994). The cultural politics of English as an international language. London and New York: Longman.

Pert, C. (1997). Molecules of emotion: The science behind mind-body medicine. New York: Touchstone Books.

Rees, W. (1999). Patch disturbance, ecofootprints, and biological integrity: Revisiting the limits to growth. Or Why industrial society is inherently unsustainable. Vancouver, BC: University of British Columbia, the Integrity Project.

Rees, W. (2002). Globalization and sustainability: Conflict or convergence? Bulletin of Science, Technology and Society, 22(4), 249-268.

Reyhner, J. (1997). Teaching Indigenous languages. Flagstaff, AZ: Northern Arizona University.

Shiva, V. (1993). Monocultures of the mind: Perspectives on biodiversity and biotechnology. London: Zed Books.

Skutnabb-Kangas, T., \& Phillipson, R. (Eds.). (1995). Linguistic human rights: Overcoming linguistic discrimination. Berlin and New York: Mouton de Gruyter.

Snow, C.P. (1959). The two cultures. Cambridge, MA: Cambridge University Press.

Wackernagel, M., \& Rees, W. (1996). Our ecological footprint: Reducing human impact on the Earth. Gabriola Island, BC: New Society.

Wilson, E.O. (1998). Consilience: The unity of knowledge. New York: Vintage Books.

Wilson, E.O. (1992). The diversity of life. New York and London: Norton.

Worldwatch Institute. (2002). State of the world, 2002: A Worldwatch Institute report on progress toward a sustainable society. New York and London: Norton. 